Rozenblat, C., Zaidi, F., \& Bellwald, A. (2017). The multipolar regionalization of cities in multinational firms' networks. Global Networks, 17(2), 171-194.

\title{
THE MULTIPOLAR REGIONALIZATION OF CITIES IN MULTINATIONAL FIRMS' NETWORKS
}

Prof. Céline Rozenblat, University of Lausanne, Celine.rozenblat@unil.ch

Dr. Faraz Zaidi, University of Lausanne, farazzaidi@yahoo.com

Antoine Bellwald, University of Lausanne, Antoine.Bellwald@unil.ch

\section{ABSTRACT}

This paper identifies the most cohesive multi-polar regions of the network of world cities, which differ from the unipolar center-periphery model largely created by the high weight of central city connections. The paper implements a community detection algorithm that outlines the high densities of city networks (in relative weights). Various patterns of industries and services, which are divided into two skill levels, are identified. We use a global database of the network of 1.2 million direct and indirect ownership links between the 800,000 subsidiaries of the top 3,000 multinational groups in 2013, allowing build four comparable networks of 503 metropolitan areas. Comparing the obtained partitions with continental, regional and economic benchmarks, classes of cities partially correspond to Free Trade Zones (FTZ) but exhibit interesting cross-continental patterns. A few cities, changing their classes according to the activities, are discussed in light of the multinational firms' strategies.

\section{KEYWORDS}

MULTINATIONAL FIRMS, WORLD CITIES NETWORKS, COMPLEX SYSTEMS, CLUSTERING

\section{INTRODUCTION}

In a multi-scaled geographic system, intense economic specialization creates groups of cities that are becoming increasingly interrelated despite the distance between them. In particular, financial specialization has generated the "global city" of New York, London and Tokyo (Sassen, 1991). It is posited that other cities are connected to this central city system in a core/periphery pattern (Friedmann, 1986; Taylor, 2001; Brown et al., 2010), creating a regionalization of large zones such as the USA, the Asia-Pacific region, Euro-Germany and the Old Commonwealth (Taylor et al, 2002). Thus, the network of global cities is a complex combination of global centrality and regionalization. However, previous analyses of the regionalization of world cities worked from a strong a priori assumption of the existence of a unipolar system of cities in globalization (Taylor et al., 2002, 2013; Derudder et al., 2003; Alderson \& Beckfield, 2004; Alderson et al., 2010). Thus, regional patterns operating in parallel to global centrality may be under-evaluated.

We assume that the network density of some communities of cities reinforces the power of the highest "world cities" that constitute multi-poles, bridging their internal communities through globalization. Free Trade Zones (FTZ) may structure these cohesions, but other geographic associations may also 
Rozenblat, C., Zaidi, F., \& Bellwald, A. (2017). The multipolar regionalization of cities in multinational firms' networks. Global Networks, 17(2), 171-194.

matter to the organization of global economic linkages (Dicken, 2011; Pomfret, 2007; Rugman et al. 2012). Identifying the uneven geographical scales of these cities' communities and verifying whether they vary according to their skill levels (for industry and service) must be undertaken.

We propose to identify dense networks of cities at the world scale through a large sample of multinational firms' networks that include all types of activities. We focus on the network properties of these communities, which will be distinguished in different levels of skills for services and industries. The unipolar/multipolar organization is first discussed in relation to the regionalization of the global integration of cities (section 1); The hypotheses and clustering methods are then proposed to be implemented on a global database of networks of multinational firms in cities (section 2). We evaluate these cities' similarities with regional benchmarks and their mutual differences, underlining cities that change their classes according to the different activities (section 3) and we discuss the results (section 4).

\section{REGIONALIZATION OF CITIES BY MULTINATIONAL FIRMS}

Previous studies often begin with a classification of cities according to their roles in multinational firm networks (Taylor et al., 2002, 2013; Derudder et al., 2003; Alderson \& Beckfield, 2004). These roles differ a great deal according to the sample of activities taken into account (1.1). The combination of regionalization and the hierarchy of cities lead to a reflection on the place of the unipolar concept in the regional vision of the world (1.2). From a methodological perspective, the underlying protocols behind the clustering methods will orient the choice of network classification that we implement in this paper (1.3).

\subsection{Multiple globalizations}

The system of control between cities described by Sassen (1991) stresses a high spatial concentration of financial and specialized services in some cities for organizing industrial and service management. This development, coupled with the emergence of new corporate financial networks, leads to a vertical disintegration (Storper, 1997) and increases the complexity of multinational firms' networks (Powell, 1990). Firms coordinate their worldwide activities in a "global value chain" according to the complexity level of transactions (i.e., the ability to codify them) (Gereffi et al., 2005).

Thus, multinational companies represent "networks within networks" (Dicken, 2011, p. 121) that interact with spatial preferences, mixing national, regional and urban specializations in the development of their evolving "global production network" (Yeung, 2005; Coe et al., 2008; Dicken, 2011). Multinational firms develop sectorial activities and articulate financial and industrial activities, as well as different levels of intensive knowledge. Krätke (2014) identified a distinctive worldwide organization of multinational firms' networks for one service sector and two industrial sectors, highlighting the main 
Rozenblat, C., Zaidi, F., \& Bellwald, A. (2017). The multipolar regionalization of cities in multinational firms' networks. Global Networks, 17(2), 171-194.

urban specializations and showing that "world cities" are the most diversified. From this perspective, we consider that different groups of cities emerge according to levels of skill and industry/services distinctions, revealing different spatial strategies of 'multiple globalizations' (Krätke, 2014, p. 125) that firms articulate.

\subsection{Regionalization or unipolar organization of world cities?}

Studies on the economic regionalization of the world began with the vision of domination between countries. Myrdal (1957) and Wallerstein (1974) stated that the world can be classified into three main zones as follows: the center, the semi-periphery and the periphery (Chase-Dunn, Rubinson, 1977; Sanderson, 2005). Hymer (1972) suggested that the pattern of regionalization among cities is consistent with this hierarchy of countries, and Alderson \& Beckfield (2004) demonstrated this to be true. In contrast, Friedmann (1986) and Sassen (1991) assumed that a global network of cities would strongly differ from the system formed by countries, generating a distinctive urban system built into the "new international division of labor". This system is composed of a "complex spatial hierarchy" that integrates both "hierarchical and regional tendencies" (Derudder et al., 2003; Liu et al., 2012; Taylor et al., 2013). Hierarchy is herein conceived as a unipolar organization around the most central world cities. The comparison that Wall et al. (2011) made between the assumptions of Alderson \& Beckfield and Taylor et al., demonstrates the difficulty in distinguishing the unipolar world from a regionalization that would underline multi-polar regions in these cities' complex networks.

\subsection{Clustering methods and identification of multi-polar regionalization}

Previous approaches applied to world cities in multinational firms' networks often include the unipolar concept introduced at three levels of the analysis: in the data, in the methodology and in the interpretation. For the data, the construction of the Globalization and World Cities group (GaWC) networks, which is based on a [firms $X$ cities] matrix, builds regionalization on the spatial overlaps of the expansions of various firms (Taylor, 2001; Neal, 2012). When clustering based on cliquishness was applied, all strongly connected cities were present in every clique (Derruder \& Taylor, 2005), which underlines their unipolar centrality in the world cities system. From a methodological perspective, Alderson \& Beckfield (2004) used block modeling, taking into account the structural equivalence between "levels of cities", and compared these membership blocks of cities with the centrality of their countries (according to Bollen \& Appold [1993]), which verified the core-periphery organization. The unipolar outputs of these two approaches largely result from the weight of the strongly connected cities that are, in fact, more likely to be linked to numerous cities and to create a unique central pole. Neal (2013) identified this bias in the GaWC data, proposing a "random sorting process" that removes the mass effects. 
Rozenblat, C., Zaidi, F., \& Bellwald, A. (2017). The multipolar regionalization of cities in multinational firms' networks. Global Networks, 17(2), 171-194.

The Complex System Sciences (CSS) clustering methods developed classifications of networks according to local densities forming "communities" or "clusters" (Girvan \& Newman, 2002; Fortunato, 2009; Sathik et al., 2011). Community detection methods, which are applied on weighted networks, standardize the calculation by the edge weights (Newman, 2004). These methods have already been applied to airplane flows connections, revealing regionalization patterns of cities that were consistent with those of the main continents (Guimera et al., 2005; Rozenblat et al., 2013). Neal (2014), using the CSS method of Louvain clustering (Blondel et al., 2008), compared the various clusterings of US cities' air traffic networks, finding continuous regions of cities in North America. Every application for airline traffic output produces clear geographical regions rather than a core-periphery pattern. This can be explained by the two well known main factors forming these networks: weight of cities and geographic distances, which together form a gravitational model that is well-known in geography (Ravenstein, 1885; Reilly, 1931) and was recently rediscovered by physicists for social phenomena (Barthelemy, 2011). In CSS methods standardizing the weights of cities, distance matters more and underlines regional aspects of these network organizations.

Because the world cities' system of multinational firm networks also partially integrates some gravitational properties (Wall et al., 2011; Rozenblat, 2015), we assume that applying these clustering methods to this network would underline the regional aspects of world cities. We can assume further that the resulting clusters would vary according to type of activity and would be closer to geographical delineation for unskilled activities than for skilled activities that are more globalized through specialized international cities.

Moreover, the concentration of internal links or the concentration of external links inside the cluster in some nodes reveals internal hierarchies (Guimera et al., 2005) that outline the polarization of the clusters following the classical definition of "polarized region" as opposed to "homogeneous region" (Friedmann, 1967), although the term "polarization" has other meanings of opposition between social groups (Esteban \& Ray, 1994) or for the diversity of nodes' connections (Van Nuffel et al., 2010).

Clusters also include uneven levels of openness that are often globally evaluated at the scale of the graph, with the clustering index (Watts, Strogatz, 1998) and at the scale of the nodes with the participation index (Guimera et al., 2005). At the cluster level, Melançon \& Rozenblat (2013) introduced the closeness index (share of a cluster's internal linkages that remain internal), which differs from the closeness centrality measured at the level of the nodes (Beauchamp, 1965).

Thus, the polarization and closeness indices reveal two complementary aspects of clusters that are not directly linked: the concentration of outreach linkages in one city (Polarization) and the internal cohesion of the cities in each cluster (closeness). However, one can assume that the polarization of clusters can be correlated with their closeness due to the domination of one city. 
Rozenblat, C., Zaidi, F., \& Bellwald, A. (2017). The multipolar regionalization of cities in multinational firms' networks. Global Networks, 17(2), 171-194.

2 Methodological premises underlining the multi-polar regionalization of world cities

The network approach will help detect multi-polar aspects in the regionalization of world cities by evaluating how communities mutually interact with one another or how they are internally organized.

\subsection{Building cities' systems using multinational firms' networks}

To determine the position of cities within these multinational firm networks, we first constructed a database consisting of the world's top 3,000 companies, based on their turnover (Orbis, Bureau Van Dijk, 2013, Fig.1.a), and their 800,000 direct and indirect subsidiaries located around the world. These subsidiaries are connected by 1.2 million financial links operating with all successive steps. This set of networks is similar (but larger) to previous datasets.

We aggregated these groups' networks at the city level (Fig.1.b and Fig.1.c) based on the location of each of the 800,000 subsidiaries (Fig. 1.a).

Figure 1: Building data: from individual networks of firms to city networks

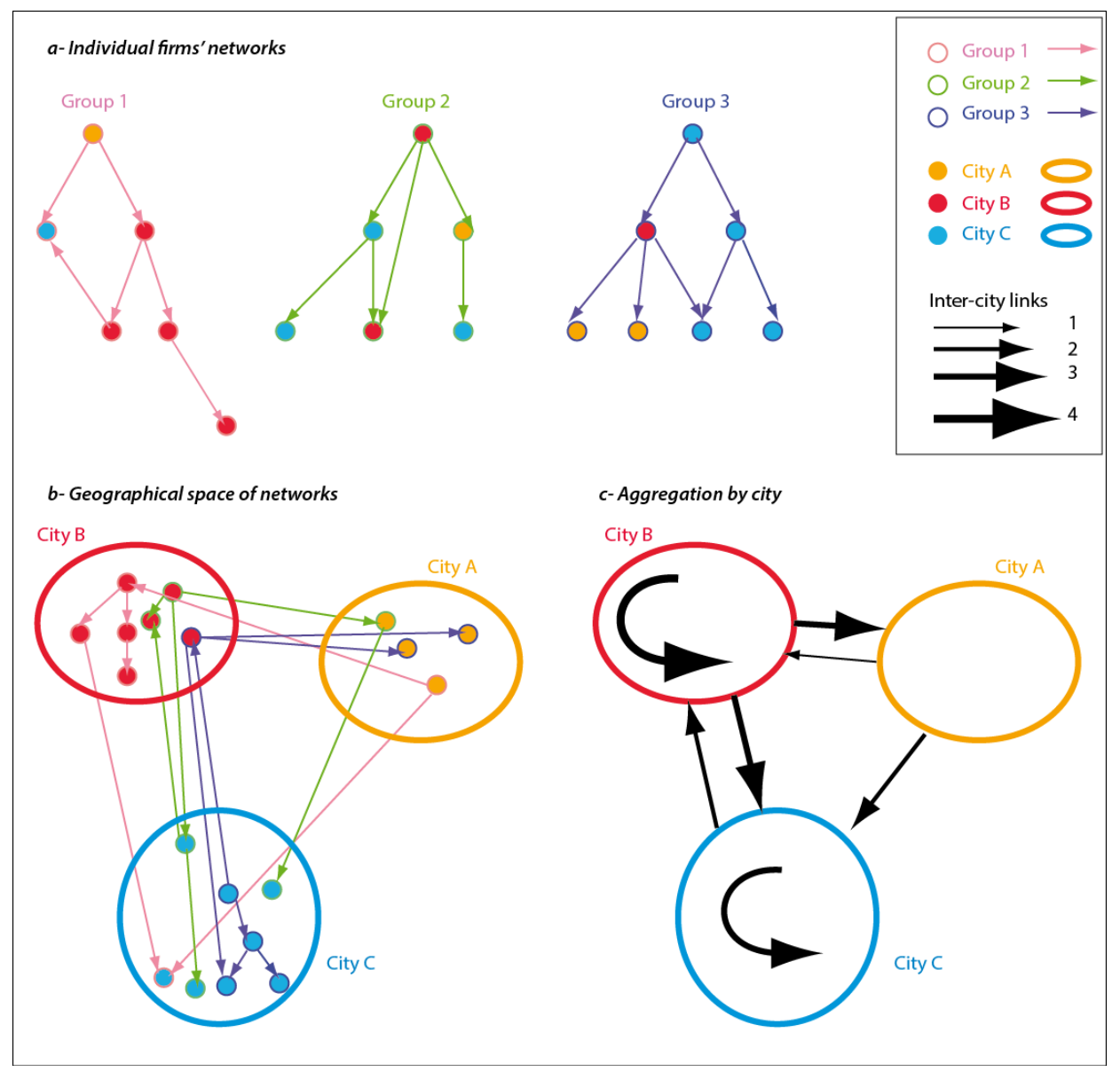

(C) Rozenblat, Zaidi, Bellwald, 2015

To aggregate the firms' location within comparable "cities", metropolitan areas were identified and delineated as "Large Urban Regions" (LUR) ${ }^{1}$. Firms' linkages were aggregated by LUR using their origin and destination locations. This process yielded a matrix linking 1,205 cities around the world. These 
Rozenblat, C., Zaidi, F., \& Bellwald, A. (2017). The multipolar regionalization of cities in multinational firms' networks. Global Networks, 17(2), 171-194.

areas contain more than $85 \%$ of the overall links in the database ${ }^{2}$. The intercity relationships are oriented, and they are weighted by aggregating firms' links by pairs of cities (removing intra-urban linkages) (Fig. 1.c).

We also considered different geographical territories, which will constitute benchmarks with which to compare empirical clustering. The UNCTAD list of FTZs (2013) includes overlapping zones. We attributed a unique relevant membership to each country. Two other benchmarks were built as follows: seven large continents (UN, 2013) and geographical proximities (orthodromic distances).

\subsection{Networks of multinational firms by their level of knowledge of activities}

To distinguish the globalization of industry/services and of high/low skill levels, we adopted the OECDEC classified activities (2009). This classification considers firms "as knowledge intensive if tertiary educated persons employed represent more than 33\% of the total employment in that activity" (OECD, 2009). The OECD produced two distinct aggregations (high and low) for industries and for services in four categories:

- High tech and low tech for industry

- $\quad$ Knowledge intensive services (KIS) and less knowledge intensive services (LKIS) for services Activities were attributed to each single firm and its ascendant linkages (a group can encompass several activities). We thus created a four-layered network (Fig.2).

Figure 2: Multi-layered city networks

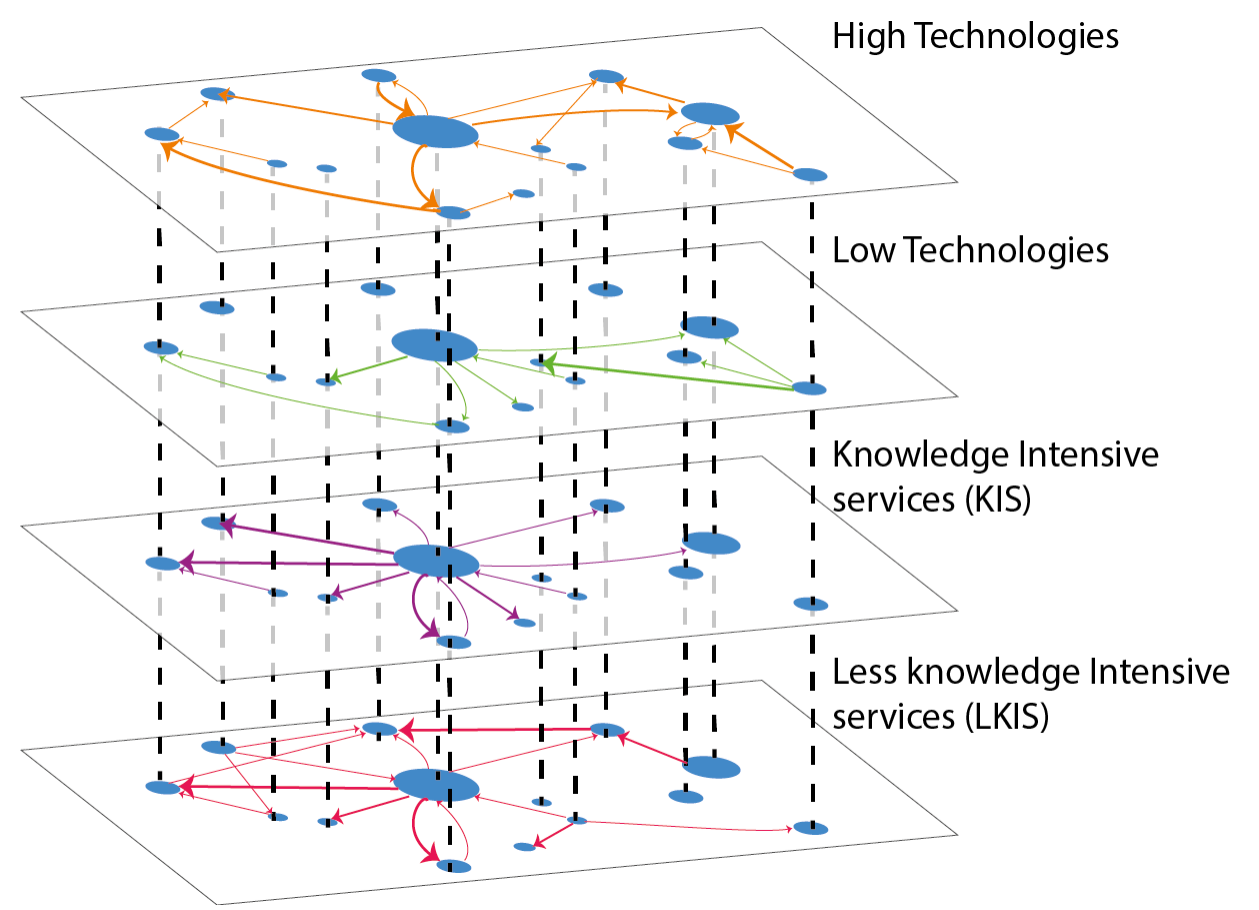

(C) Rozenblat, Zaidi, Bellwald, 2015

To compare these four layers, it was necessary to have the same number of cities; therefore, we kept only those cities present on all four levels (503 cities encompassing more than $90 \%$ of the total linkages). The 612,798 remaining links were aggregated by city couple in the multilayered network. 
Rozenblat, C., Zaidi, F., \& Bellwald, A. (2017). The multipolar regionalization of cities in multinational firms' networks. Global Networks, 17(2), 171-194.

\subsection{Clustering method}

The CSS literature defines the detection of communities or clusters as the identification of groups of nodes densely connected to one another and sparsely connected to other clusters (Schaeffer, 2007). Numerous algorithms were classified according to partitional/hierarchical, divisive/agglomerative, and fuzzy/hard properties (Jain et al., 1999). Algorithms also differ if they can be applied to directed/undirected networks, weighted/non-weighted networks or tree-like networks (Fortunato, 2009; Schaeffer, 2007). Another important distinction is the use of local and global optimization methods (Schaeffer, 2007). Local methods attempt to optimize local functions, such as modularity (Newman, 2004), which is a measure of the cohesiveness of groups (high intra-cluster edges vs. low inter-cluster edges). On the other hand, global optimization methods require information on the entire network structure (heavy computation); thus, they are unsuitable for large datasets (Fortunato, 2009). Another popular categorization for the clustering algorithms is dynamic processes, such as random walks, spin models, and information propagation (Pons \& Latapy, 2004). These methods have produced several fast and accurate algorithms (Fortunato, 2009).

We selected seven appropriate methods for weighted and oriented data belonging either to local or global optimization methods ${ }^{3}$, and we compared them with modularity (Girvan \& Newman, 2001; Clauset et al., 2004; Newman, 2012) ${ }^{4}$ (Tab. 1).

Table 1: Comparison of clustering algorithms

\begin{tabular}{|l|l|l|}
\hline & Algorithm & Modularity \\
\hline 1 & Edge Betweenness (Girvan \& Newman, 2002) & 0.02 \\
\hline 2 & Walk Trap (Pons and Latapy, 2004) & 0.12 \\
\hline 3 & Info Map (Rosvall et al.,2009) & 0.29 \\
\hline 4 & Label Propagation (Raghavan et al., 2007) & 0.03 \\
\hline 5 & Fast Greedy (Newman, 2004) & 0.31 \\
\hline 6 & Louvain (Blondel et al., 2008) & 0.31 \\
\hline 7 & Spin Glass (Reichardt and Bornholdt, 2006) & 0.36 \\
\hline
\end{tabular}

(C) Rozenblat, Zaidi, Bellwald, 2015

The best results (high modularity) were obtained using the Spin Glass clustering algorithm proposed by Reichardt and Bornholdt (2006). The Spin Glass algorithm ${ }^{5}$ has several advantages, including that the number of clusters do not need to be known a priori.

\subsection{Comparing clustering communities' similarities}

The resulting clusters are compared with the benchmarks of regional areas. A number of cluster similarity measures have been proposed recently (Lancichinetti \& Fortunato, 2009). We use the most widely accepted method, the Normalized Mutual Information (NMI) method, which was proposed by Danon et al. (2005). Given two partitional structures of a network, the calculation of NMI returns a value in a range between 1 (perfect similarity) and 0 (complete dissimilarity). 
Rozenblat, C., Zaidi, F., \& Bellwald, A. (2017). The multipolar regionalization of cities in multinational firms' networks. Global Networks, 17(2), 171-194.

3 Clustering world cities according to multinational firm networks with different knowledge levels

The Spin Glass clustering applied to the 503 cities results in one total clustering and four clusterings for each sub-network (five clusterings). General comparisons of the different clustering results (3.1) will be explained by their respective characteristics (3.2). More specific comparisons will also permit to better interpret the changing community membership of cities depending on the various activities (3.3).

\subsection{General comparisons of clustering results}

The resulting five clusters can be compared according to their general characteristics. Considering the modularity index (Tab.2), the first main result is that lower modularity indices qualify the clustering outputs of the higher levels of skill (HIGH-TECH and KIS). This modularity index is not correlated to other properties of the network, and it does not vary with the average internal links because it measures both existing and non-existing edges.

Table 2: Application of Spin Glass clustering by the skill levels of multinational firm networks

\begin{tabular}{|c|c|c|c|c|c|c|c|c|}
\hline & $\begin{array}{l}\text { Nodes } \\
\text { (Cities) } \\
\text { Number }\end{array}$ & $\begin{array}{c}\text { Total } \\
\text { Weighted } \\
\text { Edges }\end{array}$ & $\begin{array}{c}\text { Density } \\
\text { (total weighted } \\
\text { edges/nodes number) }\end{array}$ & $\begin{array}{c}\text { Alpha Power } \\
\text { Law }\end{array}$ & $\begin{array}{c}\text { Clustering } \\
\text { Coefficient } \\
\text { (Triads) }\end{array}$ & $\begin{array}{l}\text { Modularity of } \\
\text { Spin Glass } \\
\text { Clustering }\end{array}$ & $\begin{array}{c}\text { Number } \\
\text { of Clusters }\end{array}$ & $\begin{array}{l}\text { Average } \\
\text { Internal } \\
\text { Links (\%) }\end{array}$ \\
\hline HIGH-TECH & 503 & 76,339 & 152 & 1.71 & 0.30 & 0.31 & 7 & $70 \%$ \\
\hline LOW-TECH & 503 & 55,653 & 111 & 1.73 & 0.28 & 0.37 & 9 & $83 \%$ \\
\hline $\begin{array}{l}\text { KIS : KNOWLEDGE-INTENSIVE } \\
\text { SERVICES }\end{array}$ & 503 & 208,562 & 415 & 1.54 & 0.29 & 0.33 & 10 & $85 \%$ \\
\hline $\begin{array}{l}\text { LKIS : LESS KNOWLEDGE- } \\
\text { INTENSIVE SERVICES }\end{array}$ & 503 & 146,938 & 292 & 1.66 & 0.30 & 0.43 & 11 & $93 \%$ \\
\hline TOTAL NETWORK & 503 & 612,798 & 1,218 & 1.32 & 0.33 & 0.36 & 10 & $71 \%$ \\
\hline
\end{tabular}

(C) Rozenblat, Zaidi, Bellwald, 2015

Low modularity indices for high-skill networks mean that these communities of cities are less "cohesive" and exchange more between clusters. The result makes sense: firms that participate in highly skilled activities search for rare competencies in other communities, whereas firms that participate in less skilled activities are located closer to markets organizing their networks through stronger routines and creating more "cohesive" city communities.

The number of classes is higher for industrial activities clustering (7 for HIGH-TECH and 9 for LOW-TECH) than for services activities clustering (10 for KIS and 11 for LKIS), meaning a more partitioned organization of groups of cities that are not necessarily more cohesive. LOW-TECH with fewer clusters than KIS has a higher modularity index. The explanation of this subtle difference between the number of clusters and their modularity overlooks certain factors that will be explored later in this paper.

The comparison with benchmarks informs the proximity of the activities' networks of cities regarding regional and spatial patterns (Tab. 3). 
Rozenblat, C., Zaidi, F., \& Bellwald, A. (2017). The multipolar regionalization of cities in multinational firms' networks. Global Networks, 17(2), 171-194.

Table 3: NMI comparison of clustering of cities with several benchmarks

\begin{tabular}{|l|c|c|c|c|c|c|}
\hline $\begin{array}{l}\text { Clustering of cities } \\
\text { according to firms' } \\
\text { networks }\end{array}$ & $\begin{array}{c}\mathbf{( 1 )} \\
\text { TOTAL } \\
\text { Clustering }\end{array}$ & $\begin{array}{c}\text { (2) } \\
\text { UN 7 REGIONS }\end{array}$ & $\begin{array}{c}\text { (3) } \\
\text { Free Trade } \\
\text { Zones }\end{array}$ & $\begin{array}{c}\text { (4) } \\
\text { UN 22 SUB- } \\
\text { REGIONS }\end{array}$ & $\begin{array}{c}\text { (5) } \\
\text { Countries }\end{array}$ & $\begin{array}{c}\text { (6) } \\
\text { Distance-Based } \\
\text { Clustering }\end{array}$ \\
\hline HIGH-TECH & 0.67 & 0.62 & 0.63 & 0.59 & 0.54 & 0.54 \\
\hline LOW-TECH & 0.77 & 0.61 & 0.62 & 0.60 & 0.65 & 0.52 \\
\hline KIS & 0.86 & 0.54 & 0.58 & 0.61 & 0.77 & 0.52 \\
\hline LKIS & 0.82 & 0.52 & 0.63 & 0.63 & 0.77 & 0.52 \\
\hline AVERAGE & 0.78 & 0.55 & 0.60 & 0.60 & 0.70 & 0.52 \\
\hline TOTAL Clustering & & 0.49 & 0.50 & 0.51 & 0.61 & 0.55 \\
\hline
\end{tabular}

(C) Rozenblat, Zaidi, Bellwald, 2015

Unlike industry networks, the KIS and LKIS interurban networks remain highly organized around national urban systems. The principal reason for this result is the need for services to be aware of national rules and laws that maintain strong business organization at the national level (Sassen, 2007). Conversely, HIGH-TECH interurban networks resemble national delineations for only half of their aspects, implying an extended international organization based on highly specialized city networks. These networks remain largely (two-thirds) within their respective FTZs.

Approximately $50 \%$ similarity is observed between every clustering and distance-based clustering, which is lower than the similarities between FTZs. This result contradicts the results that Barigozzi et al. (2011) obtained regarding international trade, where distances matter more than belonging to an FTZ, but it is not found at the same scale because here, distances are also measured between cities within the same country. Thus, distance may not be the only criterion of interurban interaction, and one can assume that the urban hierarchy of each country also matters a great deal.

\subsection{Description of the clustering results}

Clustering the entire network results in 10 clusters that can be identified by the dominant regions or countries of their cities and by their main internal links (Fig.3). 
Rozenblat, C., Zaidi, F., \& Bellwald, A. (2017). The multipolar regionalization of cities in multinational firms' networks. Global Networks, 17(2), 171-194.

Figure 3: Clustering of cities' networks with all activities

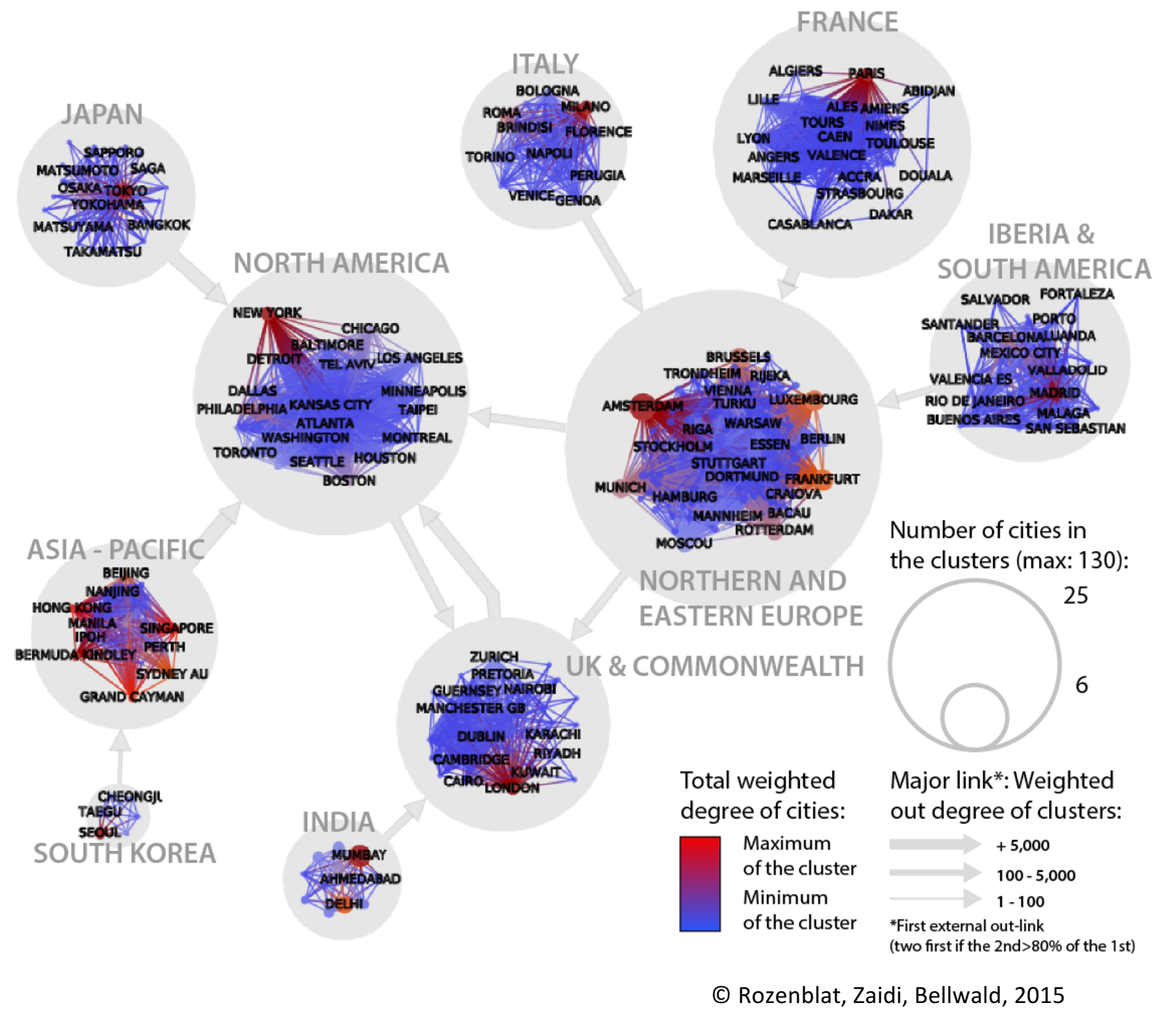

- North America encompasses 93 North American cities, including Canadian cities, Taipei, Tel Aviv and Veracruz. This class of cities is led by New York ( $16.5 \%$ of the internal links), followed by Philadelphia (9.6\%), Chicago (5.8\%) and Boston (5.3\%).

- The Asia-Pacific region is dominated by Chinese cities (Hong Kong: 17\%, Beijing: 13.4\%, Shanghai: 8.6\%), regrouped Southeast Asian cities (Singapore, Kuala Lumpur) and Australian cities (Sydney: 6\%, Melbourne: 3\%, Perth and Brisbane). This class of cities includes tax havens, such as Grand Cayman (8\%), Bermuda Kindley (10\%) and Tortola (Virgin Islands).

- Japan includes 31 cities as follows: all Japanese cities plus Bangkok, Jakarta and Maastricht. The class is dominated by Tokyo, which claims $45 \%$ of the linkages, and Osaka (25\%).

- South Korea: includes all six main South Korean cities. Similar to Tokyo, Seoul claims $46 \%$ of the internal links, and Pusan claims $20 \%$.

- The Indian community of 10 cities highlights the network cohesion of this sub-continental country, and also includes Mauritius and Colombo (Sri Lanka). Mumbai dominates this class with $36 \%$ of the internal links, followed by Delhi with $23 \%$ and Chennai with $8 \%$. 
Rozenblat, C., Zaidi, F., \& Bellwald, A. (2017). The multipolar regionalization of cities in multinational firms' networks. Global Networks, 17(2), 171-194.

European cities are clustered into five communities:

- Northern and Eastern Europe comprise 130 cities, which include Russian and Turkish cities. Although Amsterdam possesses the most important relationships ( $8.3 \%$ of internal links), it does not dominate. Many other cities, such as Vienna, Frankfurt, Brussels, Moscow, Luxembourg, Rotterdam, Hamburg, Munich and Warsaw, interact equally, with each concentrating internal links between $5 \%$ and $3 \%$.

- The UK and Commonwealth regions are comprised of 49 cities and dominated by London (35\% of total internal links). This community is the most spatially widespread community. In addition to UK and Irish cities, the UK and Commonwealth regions encompass Swiss, Middle Eastern (Abu Dhabi, Kuwait, Riyadh, Amman and Karachi) and African cities (South Africa's four main cities), as well as African capitals, such as Cairo, Lagos, Nairobi and Gaborone.

- The Iberian and South American group of cities is dominated by Madrid, with $35 \%$ of the internal links, and Barcelona with 14\%, followed by Bilbao, Lisbon, Sao Paulo, Seville, Valencia, Rio de Janeiro, Mexico City, Santiago de Chile and Buenos Aires.

- The French group of cities is dominated by Paris (39\% of the total internal links), and includes former French colonial cities in Africa (Tunis, Algiers, Douala, and Dakar) and French-speaking capitals (Accra).

- Another national network includes the 35 Italian cities of our dataset plus Lugano (an Italianspeaking city in Switzerland).

The system of dominant relationships between clusters (Fig.3) highlights the centrality of three of the clusters: the North American cluster, the Northern and Eastern European cluster, and the UK and Commonwealth cluster. These three clusters dominate most of the links between firms' investments going to or coming from other clusters of cities ( $74 \%$ of the total weighted linkages between clusters). Compared with the different clustering results proposed by Derruder et al. (2003) and completed by Liu et al. (2013), as well as with those calculated by Alderson \& Beckfield (2004), the Spin Glass clustering method disconnects the main global cities, integrating them into their appropriate regional or cultural groups.

In this form of regional organization, the more that global cities concentrate a large part of the investments controlled or attracted by the cluster's cities to/from outside the cluster (polarization), the more closed the cluster, verifying our first hypothesis. We plotted these two internal properties (Fig.4). 
Rozenblat, C., Zaidi, F., \& Bellwald, A. (2017). The multipolar regionalization of cities in multinational firms' networks. Global Networks, 17(2), 171-194.

Figure 4: Polarization and closeness of clusters for the TOTAL network

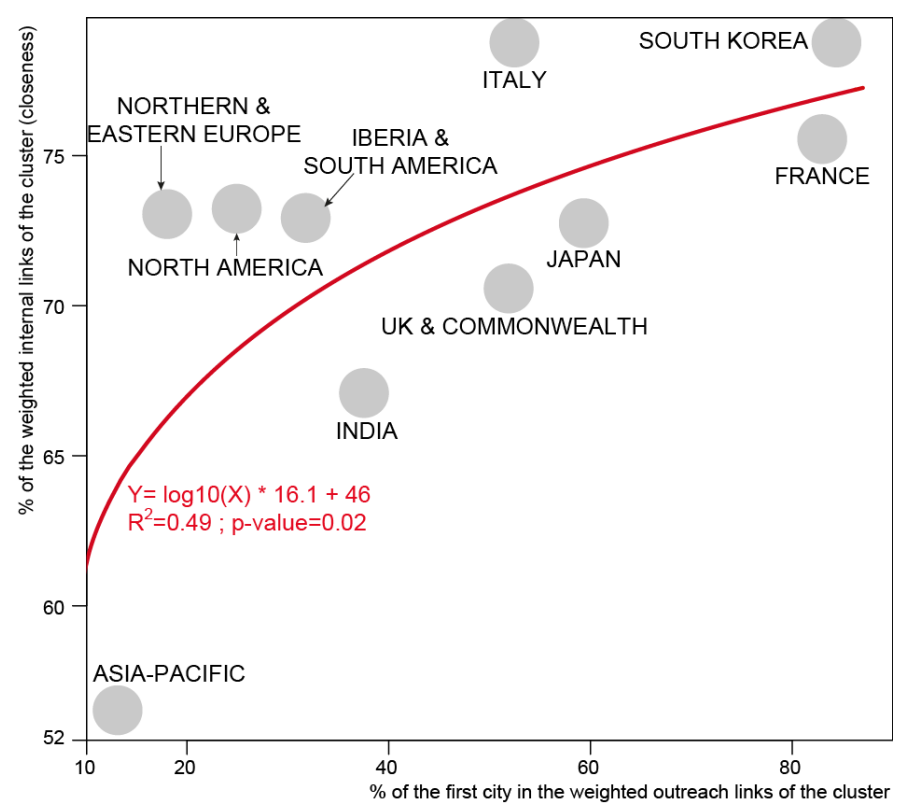

(C) Rozenblat, Zaidi, Bellwald, 2015

Some clusters are very polarized around one city based on either internal or external links (Paris for France, Seoul for South Korea, Tokyo for Japan, Milan for Italy, London for the UK and Commonwealth) and are closed systems. Other clusters are multi-polar systems with lower levels of closeness (North America, Northern and Eastern Europe, Iberia and South America, Asia-Pacific).

The less integrated cities within the clusters, determined by their share of internal linkages (Tab.4), are either anomalies of geographical membership, such as Maastricht in the Japanese cluster and Mauritius in the Indian cluster, or cities that could create bridges between clusters, such as South American cities that are partially associated with North America or Europe, Swiss cities that are largely included in the UK and Commonwealth cluster and integrated with all other clusters, and tax havens, such as Bermuda Kindley.

Table 4: Cities with the lowest integration in clusters (less than 30\%)

\begin{tabular}{|c|c|c|c|}
\hline Large Urban Region & COUNTRY & CLUSTER & $\begin{array}{l}\text { Linkages of the city } \\
\text { inside the cluster } \\
\text { (in \% of the total } \\
\text { linkages of the city) }\end{array}$ \\
\hline MAASTRICHT & NETHERLANDS & JAPAN & 11.6 \\
\hline MANILA & PHILIPPINES & ASIA / PACIFIC & 13.9 \\
\hline JAKARTA & INDONESIA & JAPAN & 14.6 \\
\hline BANGKOK & THAILAND & JAPAN & 18.1 \\
\hline QUITO & ECUADOR & IBERIA \& SOUTH AMERICA & 19.1 \\
\hline CARACAS & VENEZUELA & IBERIA \& SOUTH AMERICA & 19.3 \\
\hline ACCRA & GHANA & NORTH AMERICA & 21.3 \\
\hline COLOMBO & SRI LANKA & INDIA & 21.4 \\
\hline GUADALAJARA & MEXICO & IBERIA \& SOUTH AMERICA & 21.4 \\
\hline ZURICH & SWITZERLAND & UK \& COMMONWEALTH & 22.6 \\
\hline MEXICO CITY & MEXICO & IBERIA \& SOUTH AMERICA & 23.7 \\
\hline PANAMA CITY & PANAMA & IBERIA \& SOUTH AMERICA & 24.8 \\
\hline MAURITIUS & MAURITIUS & INDIA & 25.9 \\
\hline SAO PAULO & BRAZIL & IBERIA \& SOUTH AMERICA & 26.5 \\
\hline CAIRO & EGYPT & UK \& COMMONWEALTH & 26.7 \\
\hline SAO JOSE DOS CAMPOS & BRAZIL & IBERIA \& SOUTH AMERICA & 26.9 \\
\hline BERMUDA KINDLEY & BERMUDA & ASIA / PACIFIC & 27.1 \\
\hline GENEVA & SWITZERLAND & UK \& COMMONWEALTH & 28.4 \\
\hline BUENOS AIRES & ARGENTINA & IBERIA \& SOUTH AMERICA & 29.8 \\
\hline
\end{tabular}


Rozenblat, C., Zaidi, F., \& Bellwald, A. (2017). The multipolar regionalization of cities in multinational firms' networks. Global Networks, 17(2), 171-194.

Clustering derived using the same methodology for the four activity networks allows for a better understanding of the general network. We briefly describe each clustering but focus on their main similarities and differences. The main difference in the composition of the clusters lies in the difference between industrial networks and service networks (Tab.5). In particular, HIGH-TECH clusters differ the most from other clusters. The two closest clusterings are the KIS and LKIS ones.

Table 5: NMI comparison of the clustering of cities by activity skill levels

\begin{tabular}{|l|r|r|r|r|}
\hline & $\begin{array}{c}\text { HIGH- } \\
\text { TECH }\end{array}$ & $\begin{array}{c}\text { LOW- } \\
\text { TECH }\end{array}$ & $\begin{array}{l}\text { KNOWLEDGE- } \\
\text { INTENSIVE } \\
\text { SERVICES }\end{array}$ & $\begin{array}{c}\text { LESS } \\
\text { KNOWLEDGE- } \\
\text { INTENSIVE } \\
\text { SERVICES }\end{array}$ \\
\hline HIGH-TECH & 1 & & & \\
\hline LOW-TECH & 0.72 & 1 & & \\
\hline KNOWLEDGE-INTENSIVE SERVICES & 0.65 & 0.67 & 1 & 1 \\
\hline LESS KNOWLEDGE-INTENSIVE SERVICES & 0.56 & 0.65 & 0.78 & \multicolumn{5}{|c|}{ C Rozenblat, Zaidi, Bellwald, 2015} \\
\hline
\end{tabular}

Some clusters maintain a similar set of cities: North America, Japan, the UK and Commonwealth, and the Asia-Pacific region constitute stable clusters (Fig.5). For industrial clusters, Europe is a complete community minus the UK (and the Italian LOW-TECH cluster), and for services, Europe is much more fragmented in several clusters. Conversely, for industrial sectors, Korean cities are separated, whereas for services, they are encompassed within the Asia-Pacific cluster.

In terms of their shares of weighted links in the networks as a whole, the weights of the three dominant clusters, North America, Europe, and the UK and Commonwealth, range from $85 \%$ for high-skill activities relating to industries and services to $75 \%$ for low skill activities. This means that high-skill activity networks are concentrated inside these dominant cities' clusters, which makes sense from a diffusion of innovation perspective, where the most skill-intensive activities remain closer to central cities.

Regarding the mutual positions between clusters, the UK and Commonwealth cluster is central among the clusters for the KIS (Fig.5.C). For LKIS, the UK and Commonwealth share a central place with North America and Europe, developing major relationships with other clusters that form similar to satellites. For LOW-TECH, centrality is shared between various clusters, forming a loop of clusters. Interestingly, UK \& Commonwealth cities preferentially invest in North American cities for the higher level of skill found there (HIGH-TECH and KIS) while rather being oriented toward European cities for unskilled activities (LOW-TECH and LKIS).

To comprehend the internal organization of the clusters, we plotted the polarization of the clusters' outreach linkages in the highest city and the average level of closeness of the cities in the clusters for each activity (Fig.6). 
Rozenblat, C., Zaidi, F., \& Bellwald, A. (2017). The multipolar regionalization of cities in multinational firms' networks. Global Networks, 17(2), 171-194. 
Rozenblat, C., Zaidi, F., \& Bellwald, A. (2017). The multipolar regionalization of cities in multinational firms' networks. Global Networks, 17(2), 171-194.

Figure 5: Clustering of cities' networks by activity skill levels

\section{A- HIGH TECHNOLOGIES}

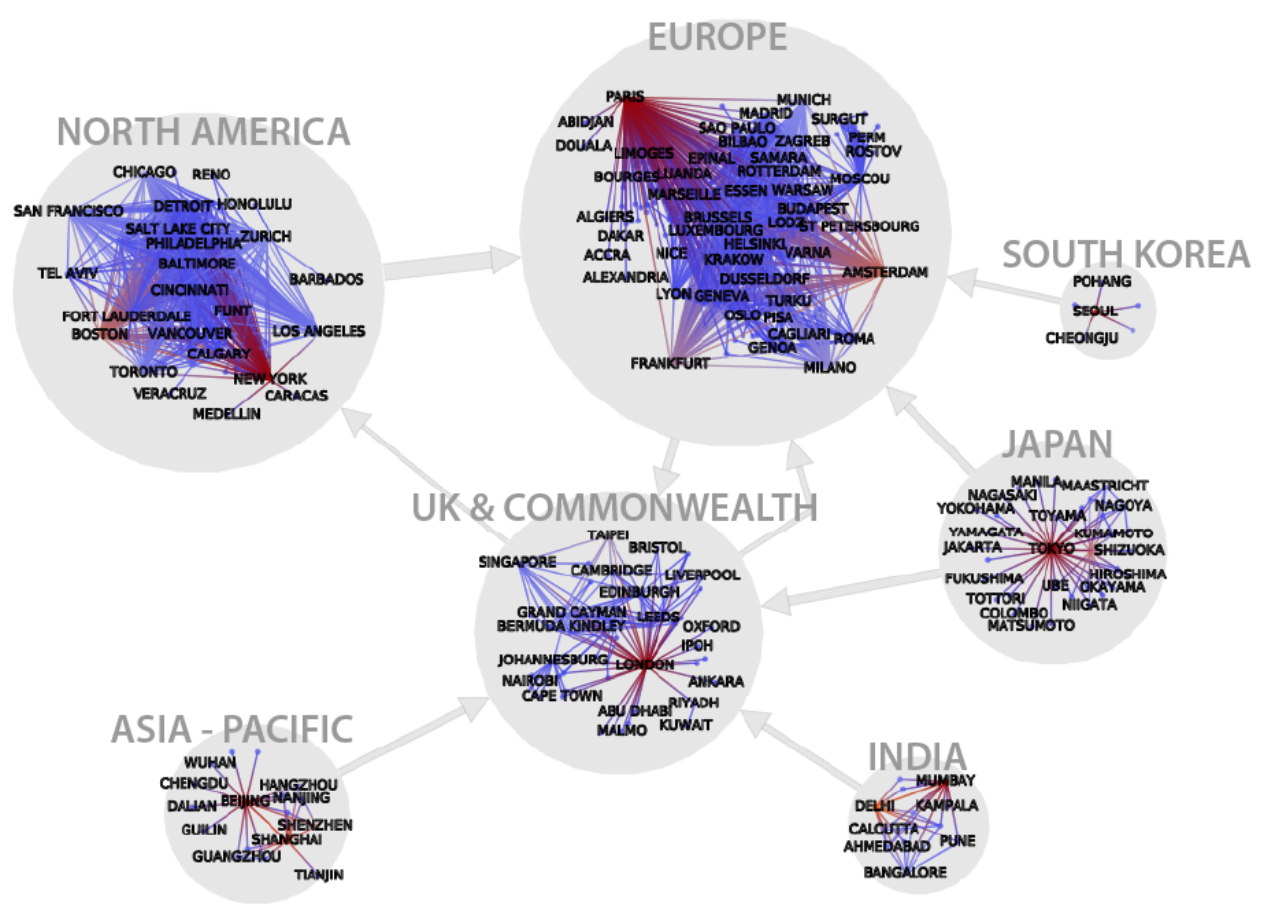

B- MIDDLE AND LOW TECHNOLOGIES

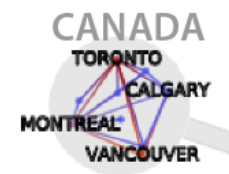

SOUTH KOREA CHEONGJU SESAN:

\section{JAPAN}

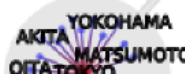

Orranopio

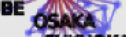

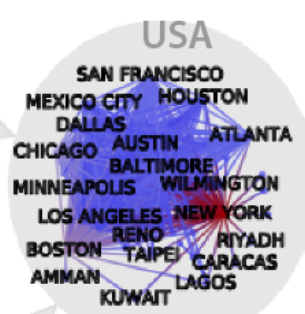

KUWATT LAEOS

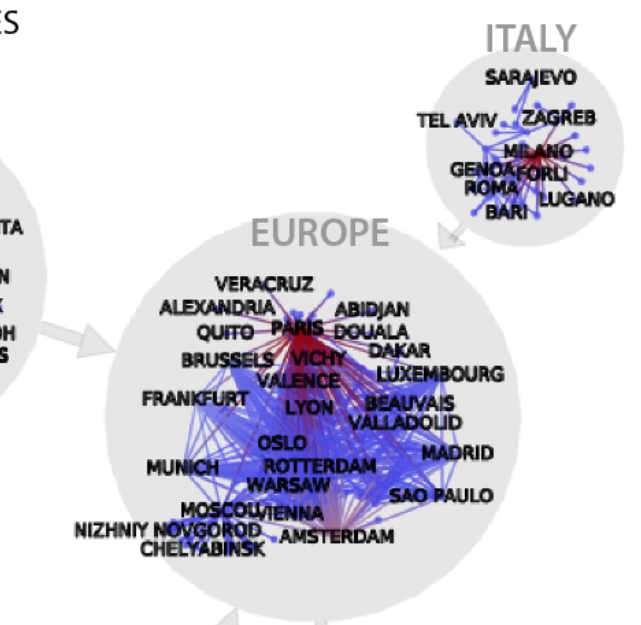

Number of cities in

the clusters (max: 275):

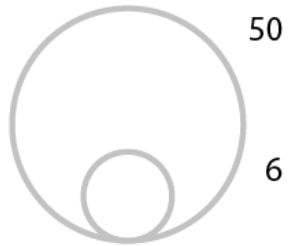

Major link*: Weighted out degree of clusters:

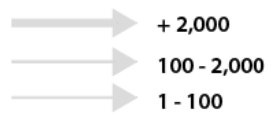

*First external out-link (two first if the 2 nd $>80 \%$ of the 1 st)

Total weighted degree of cities:

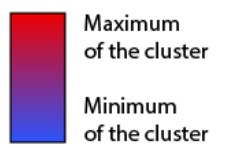

(C) Rozenblat, Zaidi, Bellwald, 2015 
Rozenblat, C., Zaidi, F., \& Bellwald, A. (2017). The multipolar regionalization of cities in multinational firms' networks. Global Networks, 17(2), 171-194.

Figure 5 (continuing): Clustering of cities' networks by activity skill levels

\section{C- KNOWLEDGE INTENSIVE SERVICES}

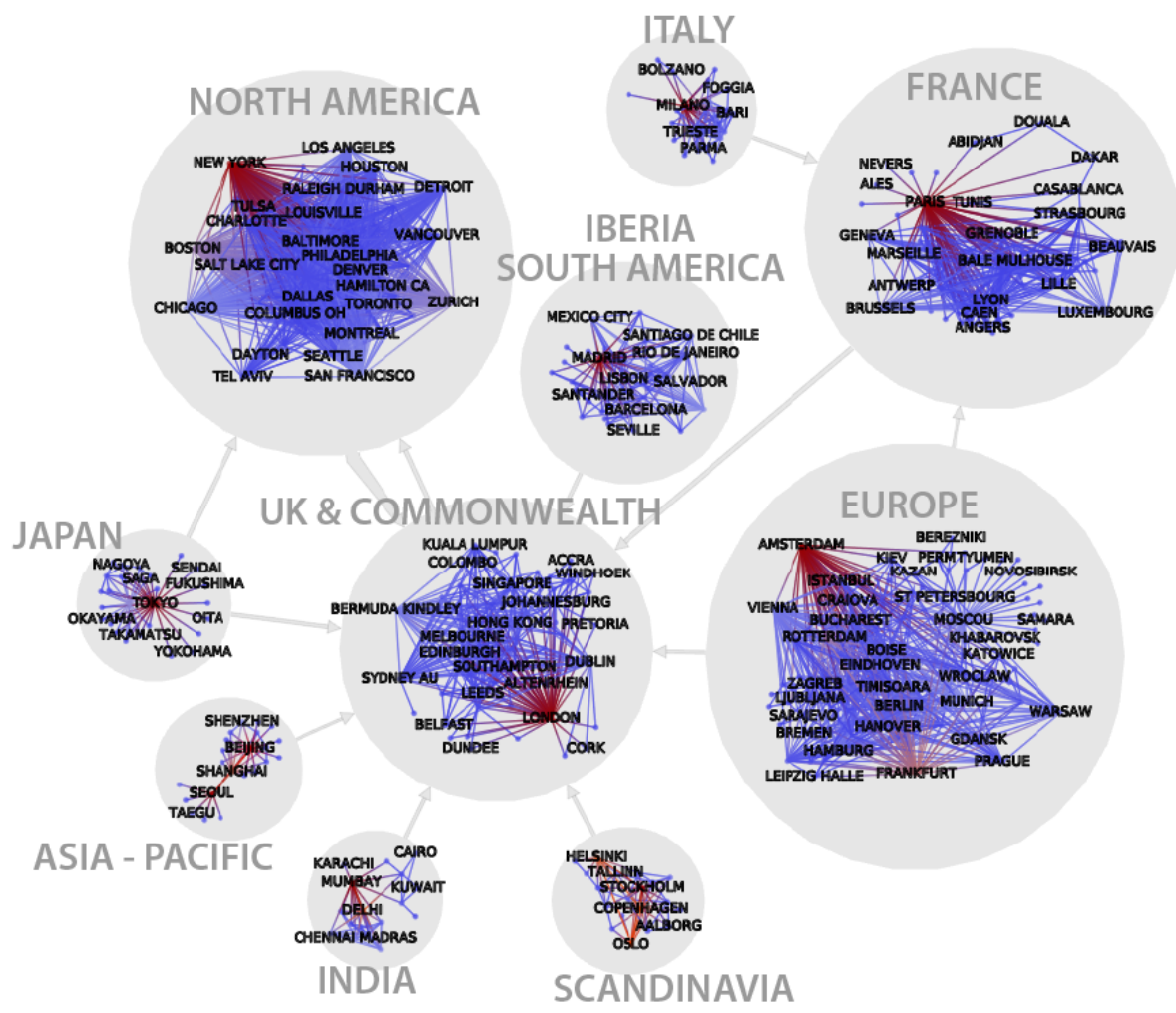

D- LESS KNOWLEDGE INTENSIVE SERVICES

\section{IBERIA}

SOUTH AMERICA

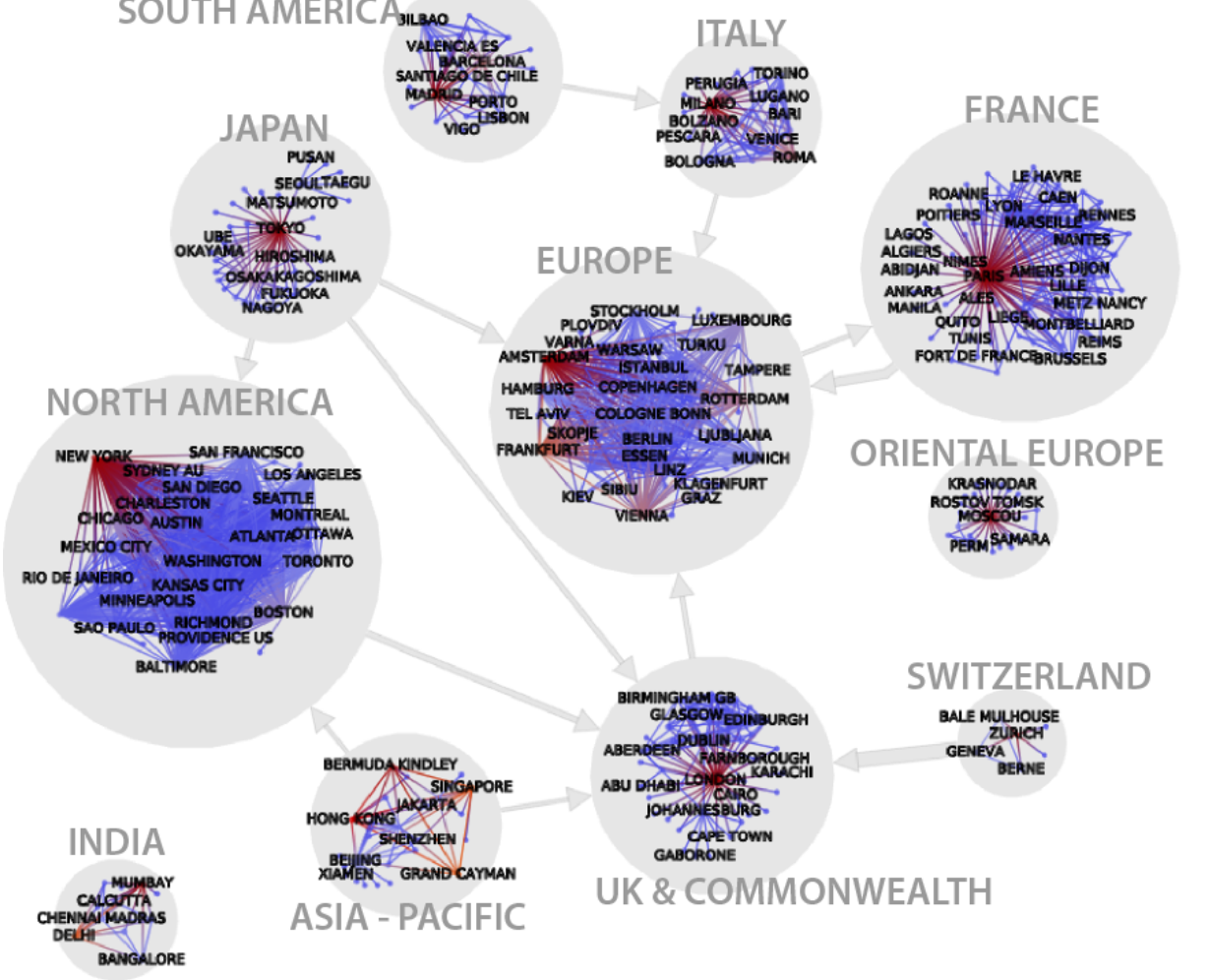

Number of cities in

the clusters (max: 108):

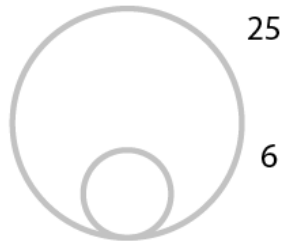

Maximum total weighted out degree of clusters*:

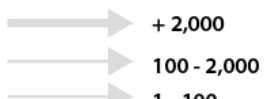

rnal out-link (two first if the 2 nd $>80 \%$ of the 1 st)

Total weighted degree of cities:

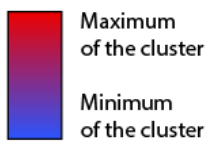


Rozenblat, C., Zaidi, F., \& Bellwald, A. (2017). The multipolar regionalization of cities in multinational firms' networks. Global Networks, 17(2), 171-194.

Figure 6: Polarization and closeness of clusters by activity level
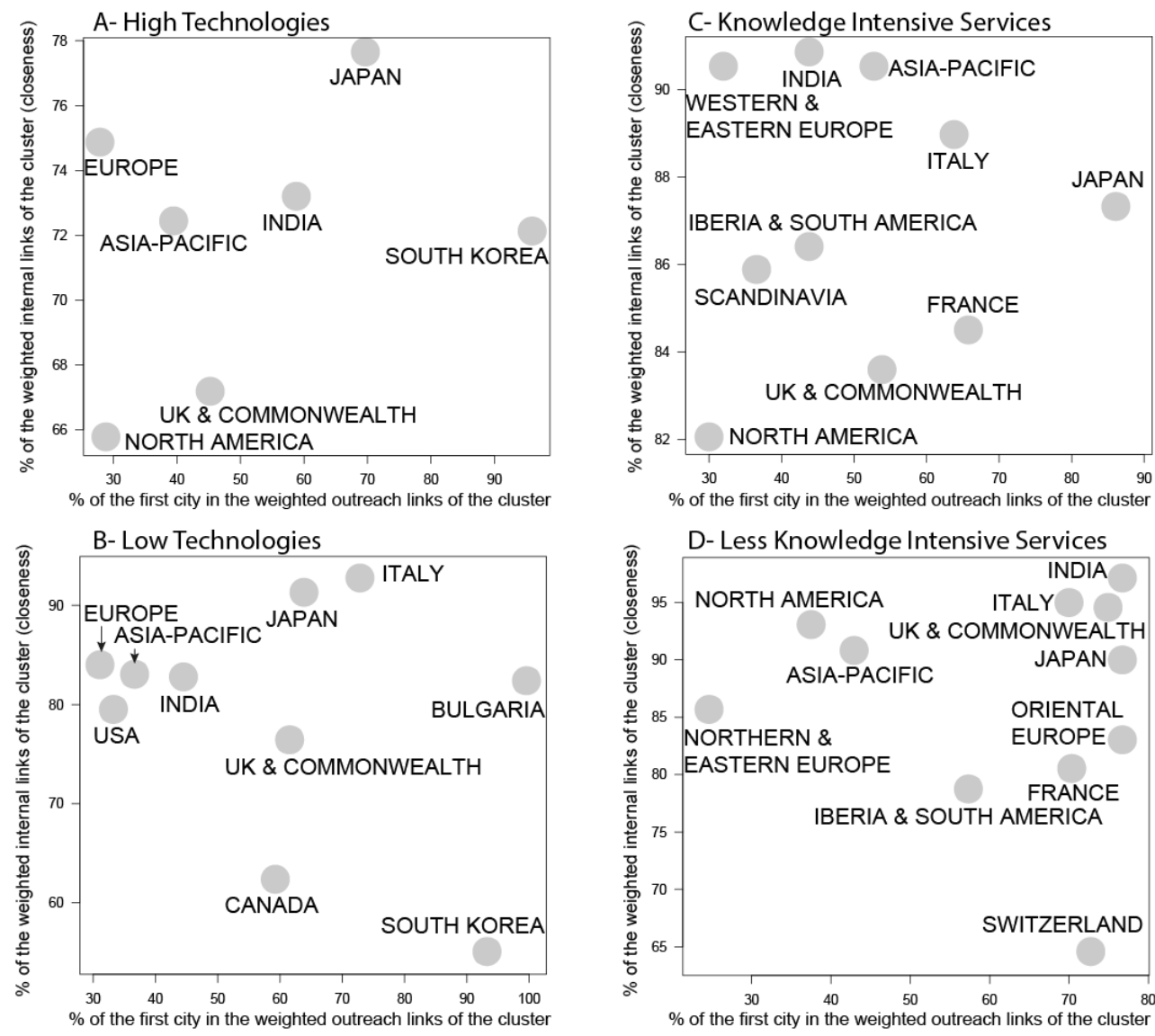

(C) Rozenblat, Zaidi, Bellwald, 2015

There is no longer correlation between the two properties of clusters. The unique regularity is visible for the North American and for the UK \& Commonwealth clusters, the two most open clusters for the more skilled activities. In these cases, the two clusters are strongly central and encompass a large number of cities. However, clusters are usually recomposed and transformed in four distinct ways:

- First, the clusters are divided into several sub-clusters between skilled and unskilled activities

- Second, cities shifting from one cluster to another can radically change the organization of the clusters. When France is aggregated to Europe, Paris becomes the most central city. Iberian and South American cities, which form a unique cluster for services, are divided between North America and Europe for industries. Thus, these two clusters are transformed by their new cities' compositions

- Third, the stable clusters are generally dominated by the same city, but there are exceptions, such as the Asia-Pacific cluster, which is dominated by Beijing. However, the Asia-Pacific cluster is dominated by Hong Kong for LKIS internal links, Shanghai for HIGH-TECH outreached links, and Seoul for KIS outreached links

- Fourth, the role of secondary cities matters depending on the activity. For HIGH-TECH, Taipei is the second city after London in the UK and Commonwealth cluster, dominating more than $15 \%$ 
Rozenblat, C., Zaidi, F., \& Bellwald, A. (2017). The multipolar regionalization of cities in multinational firms' networks. Global Networks, 17(2), 171-194.

of the total outreach links of the cluster. Osaka is second in the Japanese cluster and is particularly strong in HIGH-TECH, dominating more than $20 \%$ of the external linkages

Thus, the properties of the clusters are widely influenced by their cities' composition and by the balance between them. Shifts occur from one cluster to another and from an internal position to a different position according to activities that underline the different aspects of globalization insertion for each city.

When a city remains in the same cluster, whatever the activity, one can consider that it has a strong and deep attachment to its cluster. On the other hand, a city that changes its membership from one cluster to another reflects different forms of integration into the process of globalization. Because clusters change from one activity to another, the changing membership of cities must be considered without taking into account the major re-compositions of the clusters. For this reason, we aggregated clusters by their main compositions in five major stable communities:

- Europe: France, Italy, Spain, Europe, the UK and the Commonwealth

- North America: USA and Canada

- $\quad$ Asia: Asian cities and Korea

- Japan

- India

Among the 503 cities examined, 428 (85\%) remained in the same major stable community regardless of activity. Additionally, 75 cities moved from one cluster to another, sometimes following common patterns.

The European community has a pronounced ability to integrate cities that participate in highly skilled activities, those having the characteristics of tax havens (Bermuda Kindley, Hong Kong, Grand Cayman, Singapore, Kuala Lumpur and the Virgin Islands) and those with energetic economies (Lagos, Almaty and Astana).

However, North American cities have privileged high-skill links with South America and with highly skilled cities such as Zurich and Tel Aviv. Japanese intercity networks are also powerful in integrating HIGH/LOW-TECH Asian and even European cities. For KIS, Indian city networks integrate Middle Eastern cities such as Cairo, Alexandria, Abu Dhabi, Riyadh, Amman and Kuwait.

\section{Discussion of the multipolar organization of the world cities system}

Overall, the analysis supports the notion of the world cities' network as a "multipolar" system because of these cohesive clusters that form dense poles of interacting cities. The shift from a unipolar to a multipolar vision of world cities corresponds to a wider change in the comprehension of the feedback 
Rozenblat, C., Zaidi, F., \& Bellwald, A. (2017). The multipolar regionalization of cities in multinational firms' networks. Global Networks, 17(2), 171-194.

processes maintaining or transforming the distribution of power between cities and forming the basis for the predominance of some of these cities. The classical core/peripheral system is replaced by a twolevel system considering cores and peripheries both between and within clusters. This double level between and inside clusters expresses a networking process dictated by steps in which firms' investments often enter into a cluster of cities by top cities to reach other cities, where they diffuse their investments. FTZs are important in this stepwise process, participating in the feedback maintenance and reinforcement of the global strength of the central cities of each cluster, and they also reinforce the internal cohesion of each cluster. In this sense, global linkages between clusters and local linkages inside clusters are intertwined.

Most of the dominant cities of the central clusters correspond to the cities that are classically mentioned as "world cities": London, New York, Tokyo, Paris, and Amsterdam. The regularity of these cities' centrality in the service and industrial sectors confirms the correlation highlighted by Wall \& Van der Knaap (2011). Capital cities of peripheral regions still constitute "pivotal intermediaries" for cities of their subsystems, confirming the Meyer (1986) hypothesis. However, the level of their cluster domination and their clusters' hierarchical characteristics specify the core/hinterland results of the previous studies on the regionalization of the world city networks (Taylor et al., 2002, 2013; Derudder et al., 2003; Alderson \& Beckfield, 2004). These specifications are evident in three main results.

First, the "classical world cities" do not have the same levels of dominance (polarization) in their own clusters, which induces different forms of globalization:

- On the one hand, the group of cities that dominate their clusters compose more than half of the total out-linkages of their clusters. The dominant cities are London, Tokyo, Paris, Milan and Seoul. These cities concentrate a high intermediary capacity for decision, playing a central role in the globalization of other cities in their own sub-systems. The best example of this type of worldwide role is London, encompassing global control of numerous cities around world. Other cities, such as Tokyo, Paris, Milan and Seoul, control their national urban systems.

- On the other hand, New York for North American cities, Amsterdam for Northern and Eastern European cities, and Beijing for Asian-Pacific cities belong to more distributed systems in which many cities exchange firms' linkages directly with cities from other clusters. Firms' practices exploit their combined network resources linked outside the clusters.

Second, the multipolar system of cities does not function on the same scale all over the world. The fact that some continental, inter-continental or national scales appear at the same score of modularity expresses a wide range of levels of international openness/cohesion of cities by countries and continents. For LKIS, Japanese, Korean, Indian, Chinese, French, Italian and even Swiss cities maintain a high level of national mutual interdependencies. These networks between national cities produce the 
Rozenblat, C., Zaidi, F., \& Bellwald, A. (2017). The multipolar regionalization of cities in multinational firms' networks. Global Networks, 17(2), 171-194.

same level of dependencies that exist in much wider communities, such as North America, or the UK and the Commonwealth. In this respect, Spin Glass clustering does not verify the conclusion that "clusters with low average connectivity tend to be more regionally restricted in membership" (Taylor et al., 2002, p. 885). HIGH-TECH and KIS also highlight for the UK and Commonwealth group a higher geographic magnitude than for lower skilled activities, which can be explained by the worldwide search for highly skilled, specialized competencies. For low-skilled activities, proximity matters more and this cluster is also more linked to the European cities' cluster.

Third, the inter-cluster level not only reveals the mutual position of dominant cities but also the organization of the complete sub-systems. The stable core centrality of North American, European and UK and Commonwealth cities according to their different activities is simultaneous with cities' movements: national cities create their own clusters for less skills activities for which clusters are more numerous and less dominated by the three main clusters. Cities that move from one cluster to another have a particular position in the globalization process because they are oriented toward several groups of cities according to their activities. These cities are principally located in Asia, Australia and South America, plus Zurich and Tel Aviv. Therefore, they constitute specialized or regional pivots in the expansion of the multinational firms' strategies, hosting regional or specialized centers of industry or services.

\section{Conclusion}

The systematic method of clustering borrowed from CSS allows for ordering the multipolar regional processes between cities. Clustering reveals cohesive communities that are unevenly polarized around one dominant city. In their own networks, firms articulate these skilled/less skilled activities and industrial and service functions in their global value chains. In this sense, the multi-polar city networks represent the main sub-systems of city resources for high skill/low skills in industrial and service activities practiced in worldwide firm networks. The presence of multi-polar city networks confirms the "multiple globalizations" proposed by Krätke (2014), specifying the different positions of cities in several industrial or services systems. Further analysis by sector would better highlight city specializations in specific global value chains.

In terms of policy, this new vision offers each city an overview of its main interdependencies. Therefore, this analysis may help cities build a strategy both inside the cluster to increase their linkage density, which may function as an easy form of specialization, and outside the cluster by targeting specific cities according to which groups of cities they would like to reach. The governments of cities that are permanently polarized by other cities are well aware of their dependency on these cities and attempt to diminish that dominance by fostering alternative linkages. Conversely, city governments dominated by several groups can use this property to strengthen the position of their cities by attracting new firms 
Rozenblat, C., Zaidi, F., \& Bellwald, A. (2017). The multipolar regionalization of cities in multinational firms' networks. Global Networks, 17(2), 171-194.

through targeted activities and from specific cities. Given the resilience of these cities' systems in terms of the diversity of their interdependencies, this evolution must be followed to evaluate the progression of the diversity levels of the entire system, of each community, and of each city's dependency within communities.

\section{BIBLIOGRAPHY:}

Alderson, A. S., Beckfield, J. (2004). Power and Position in the World City System. American Journal of Sociology, 109(4), 811851.

Alderson, A. S., Beckfield, J., Sprague-Jones, J. (2010). Intercity Relations and Globalisation: The Evolution of the Global Urban Hierarchy, 1981--2007. Urban Studies, 47(9), 1899-1923.

Barigozzi, M., Fagiolo, G., Mangioni, G. (2011). Identifying the community structure of the international-trade multi-network. Physica A: Statistical Mechanics and its Applications, 390(11), 2051-2066.

Barthelemy, M. (2011). Spatial networks. Physics Reports, 499(1), 1-101.

Beauchamp, M. A. (1965). An improved index of centrality. Behavior Science, 10(2), 161-163.

Blatt, M., Wiseman, S., Domany, E. (1996). Superparamagnetic Clustering of Data. Physical Review Letters, 76(18), 3251-3254.

Blondel V. D., Guillaume J.-L., Lambiotte R., Lefebvre E. (2008). Fast unfolding of communities in large networks, Journal of Statistical Mechanics: Theory and Experiment, IOP Publishing.

Bollen, K. A. and Appold S. J. (1993). National Industrial Structure and the Global System, American Sociological Review 58(2): 283-301.

Brown, E., Derudder, B., Parnreiter, C., Pelupessy, W., Taylor, P. J., Witlox, F. (2010). World City Networks and Global Commodity Chains: towards a world-systems' integration. Global Networks, 10(1), 12-34

Chase-Dunn C. and Rubinson R. (1977). Toward a structural perspective on the world-system. Politics and Society 7, 4:453-76.

Clauset, A., Newman, M. E. J., Moore, C. (2004). Finding community structure in very large networks. arXiv:cond-mat/0408187.

Coe, N. M., Dicken, P., Hess, M., Yeung, H. (2010). Making connections: Global Production Networks and World City Networks. Global Networks, 10(1), 138-149.

Danon L., Diaz-Guilera A., Duch J. Arenas A. (2005). Comparing community structure identification Journal of Statistical Mechanics: Theory and Experiment, IOP Publishing.

Derudder, B., Taylor, P. (2005). The cliquishness of world cities. Global Networks, 5(1), 71-91.

Derudder B., Taylor P.J, Witlox F., Catalano G. (2003). Hierarchical tendencies and regional patterns in the world city network: a global urban analysis of 234 cities. Regional Studies, 37(9), 875-886.

Dicken, P. (2011). Global Shift, Sixth Edition: Mapping the Changing Contours of the World Economy. Guilford Press.

Friedmann J.R. (1967). A general Theory of polarized development, Mimeo, Santiago de Chile

Friedmann J.R. (1986). The World City Hypothesis. Development and change, vol.17, 1, pp.69-84

Fortunato S. (2009). Community detection in graphs, Physics Reports, Elsevier, 2010, 486, 75-174.

Gereffi G. Humphrey J. Sturgeon T. J. (2005). The Governance of Global Value Chains. Review of International Political Economy, Vol. 12, 1, 78-104

Girvan P., Newman M. (2002). Community structure in social and biological networks. PNAS 99:8271\{8276\}.

Gereffi, G., Humphrey, J., \& Sturgeon, T. (2005). The governance of global value chains. Review of international political economy, 12(1), 78-104.

Guimerà R., Mossa S., Turtschi A., Amaral L. (2005). The worldwide air transportation network: Anomalous centrality, community structure, and cities' global roles. Proceedings of the National Academy of Sciences, 102(22), 7794-7799.

Hymer S. (1972). The multinational corporation and the law of uneven development in J. Bagwati (ed.) Economic and world order, New York, MacMillan

Jain AK, Murty MN, Flynn PJ (1999). Data clustering: a review. ACM Comput Surv 31(3):264\{323\}.

Krätke, S. (2014). How manufacturing industries connect cities across the world: extending research on 'multiple globalizations'. Global Networks, 14(2), 121-147.

Lancichinetti, A., Fortunato, S. (2009). Community detection algorithms: a comparative analysis, Physical review E, APS, 80, 056117

Liu, X., Derudder, B., Liu, Y. (2013). Regional geographies of intercity corporate networks: The use of exponential random graph models to assess regional network-formation. Papers in Regional Science, 94(1), 109-126.

Mahutga M. C., Xiulian M, Smith, D., Timberlake, M. (2010). Economic Globalisation and the Structure of the World City System: The Case of Airline Passenger Data. Urban Studies, 47(9), 1925-1947.

Melançon G., Rozenblat C. (2013). Structural analysis of networks, in C. Rozenblat and G. Melançon (eds.), Methods for 
Rozenblat, C., Zaidi, F., \& Bellwald, A. (2017). The multipolar regionalization of cities in multinational firms' networks. Global Networks, 17(2), 171-194.

Multilevel Analysis and Visualisation of Geographical Networks, Methodos Series 11, Springer, 69-80.

Meyer D. R. (1986). The World System of Cities: Relations Between International Financial Metropolises and South American Cities. Social Forces, 64(3), 553-581

Myrdal G. (1957). Economic Theory and Underdeveloped Regions, London, Duckworth. 66-86.

Neal Z. (2013). Brute Force and Sorting Processes: Two Perspectives on World City Network Formation. Urban Studies, 50(6), 1277-1291.

Neal, Z. (2014). The devil is in the details : Differences in air traffic network by scale, species, and season, Social Networks, 38, 63-73

Newman, M. E. J. (2004). ,Analysis of weighted networks, M. E. J. Newman, Phys. Rev. E 70, 056131

Newman, M. E. J. (2012). Communities, modules and large-scale structure in networks. Nature Physics, 8(1), 25-31.

OECD (2009). OSLO MANUAL: GUIDELINES FOR COLLECTING AND INTERPRETING INNOVATION DATA, OECD/European Communities, http://www.oecd-ilibrary.org

Pomfret R. (2007). Is Regionalism an Increasing Feature of the World Economy? World Economy, 30(6), 923-947.

Pons, P. Latapy, M. (2004). Computing communities in large networks using random walks, J. of Graph Alg. and App. bf, 2004, $10,284-293$

Powell, W. (1990). Neither market nor hierarchy: network forms of organization. Research in organizational behavior, 12, 295336.

Raghavan, U.N., Albert, R. and Kumara, S. (2007). Near linear time algorithm to detect community structures in large-scale networks. Phys Rev E 76, 036106.

Ravenstein, E. G. (1885). The Laws of Migration. Journal of the Statistical Society of London, Vol. 48, No. 2 (Jun., 1885), pp. 167235.

Reichardt, J., Bornholdt, S. (2006). Statistical mechanics of community detection. Physical Review E, 74(1), 016110.

Reilly, W. J. (1931). The law of retail gravitation. Knickerbocker Press, New York

Rosvall M.,Axelsson D., Bergstrom C.T. (2009). The map equation, Eur. Phys. J. Special Topics 178, 13

Rozenblat C. (2015). Inter-Cities' Multinational Firms Networks and Gravitation Model, Annals of the Japanese Association of Economic Geographers, 61, 3, 219-237

Rozenblat, C., Melançon, G., Bourqui, R., Auber, D. (2013). Comparing Multilevel Clustering Methods on Weighted Graphs: The Case of Worldwide Air Passenger Traffic 2000-2004. In Rozenblat, Melançon (eds), Methods for Multilevel Analysis and Visualisation of Geographical Networks (p. 141-154). Springer.

Rugman, A. M., Oh, C. H., Lim, D. S. K. (2012). The regional and global competitiveness of multinational firms. Journal of the Academy of Marketing Science, 40(2), 218-235.

Sanderson, S. K. (2005). World-Systems Analysis After Thirty Years: Should It Rest in Peace? International Journal of Comparative Sociology, 46(3), 179-213.

Sassen S. (1991). The Global City : New York, London, Tokyo. Princeton University Press.

Sassen, S. (2007). Sociology of globalization. New York: W.W. Norton.

Sathik, M., Senthamarai Kannan, K., Rasheed, A. (2011). Comparative analysis of community discovery methods in social networks. International Journal of Computer Applications, 14(8), 27-31.

Schaeffer S.E. (2007). Graph clustering. Computer Science Review 1(1):27\{64\}

Storper, M. (1997). The regional world: territorial development in a global economy. Guilford Press.

Taylor P.J. (2001). Specification of the World City Network. Geographical analysis, 33 (2), 181-194.

Taylor, P. J., Catalano, G., Walker, D. R. F. (2002). Exploratory Analysis of the World City Network. Urban Studies, 39(13), 2377-2394.

Taylor, P. J., Derudder, B., Hoyler, M., Ni, P. (2013). New regional geographies of the world as practised by leading advanced producer service firms in 2010. Transactions of the Institute of British Geographers, 38(3), 497-511.

United Nations (2013). Composition of macro geographical (continental) regions, geographical sub-regions, and selected economic and other groupings https://unstats.un.org/unsd/methods/m49/m49regin.htm

Van Nuffel N., Derudder B., Witlox Fr. (2010). Even important connections are not always meaningful: on the use of polarisation measure in a typology of European cities in transport networks, Tijdschrift voor Economische en Sociale Geografie, 101, 3, 333348

Wall, R. S., Burger, M. J., van der Knaap, G. A. (2011). The geography of global corporate networks: the poor, the rich, and the happy few countries. Environment and Planning A, 43(4), 904-927.

Wall, R. S., van der Knaap, G. A. (2011). Sectorial Differentiation and Network Structure Within Contemporary Worldwide Corporate Networks. Economic Geography, 87(3), 267-308.

Wallerstein, I. (1974). The Rise and Future Demise of the World Capitalist System: Concepts for Comparative Analysis. Comparative Studies in Society and History, 16(04), 387-415.

Watts, D. J., \& Strogatz, S. H. (1998). Collective dynamics of 'small-world'networks. Nature, 393(6684), 440-442. 
Rozenblat, C., Zaidi, F., \& Bellwald, A. (2017). The multipolar regionalization of cities in multinational firms' networks. Global Networks, 17(2), 171-194.

Yeung, H. W. (2005). Rethinking relational economic geography. Transactions of the Institute of British Geographers, 30(1), 3751.

${ }^{1}$ ‘Large Urban Regions’ delineated by ESPON (2012) for Europe, by the Metropolitan Statistical Areas for the USA and Canada, and by the equivalent for the main cities worldwide based on National delineations when available (IGD-UNIL Lausanne and Geodivercity in Paris).

${ }^{3}$ The seven tested algorithms are

- Edge Betweenness (Girvan and Newman, 2002) is a global algorithm based on the calculation of geodesic distances. The edges lying between all pairs of nodes are removed repeatedly to break the entire network into disconnected components, thus providing different communities.

- WalkTrap (Pons and Latapy, 2004) is a global optimization using a dynamic process of random walks to calculate the distances between different nodes based on which nodes are grouped together to form clusters using Ward's Method. Modularity is used to select the best partition.

- Info Map (Rosvall et al.,2009) is another global optimization algorithm belonging to the category of dynamic process as it also uses random walks, where the idea is to attempt to compress the information of this dynamic process, minimizing the description length of the random walk to obtain clusters.

- Label Propagation (Raghavan et al., 2007) algorithm belongs to the category of local algorithms using a dynamic process of majority voting. Randomly unique labels are assigned to individual nodes, which are subsequently updated using majority voting in the neighborhood of the vertex, which in turn results in the detection of communities.

- $\quad$ Fast Greedy (Newman, 2004) is a local clustering algorithm that aggregates nodes close to each other based on the optimization of Modularity (exposed in detail below).

- Louvain (Blondel et al., 2008) algorithm is another local optimization algorithm based on modularity, where the aggregated nodes are replaced by new nodes in the graph, thus simplifying the original graph every time a new cluster is formed. This method results in a different and faster clustering algorithm.

- Spin Glass (Reichardt and Bornholdt, 2006) clustering algorithm is based on the idea that if Potts spin variables are assigned to the vertices of a network and if the interactions are between neighboring spins, structural clusters can be found from the spin alignment of the system. Thus, a local optimization takes place to align neighboring nodes, resulting in communities.

${ }^{4}$ Mathematically, Modularity is defined as follows (Girvan \& Newman, 2002; Clauset et al., 2004; Newman, 2012):

$Q=\frac{1}{2 m} \times \sum_{v w}\left[A_{v w}-\frac{k_{v} k_{w}}{2 m}\right] \delta\left(c_{v}, c_{w}\right)$

where

$A_{v w}=\left\{\begin{array}{l}1 \\ 0\end{array}\right.$ is the edge of the graph between nodes $v$ and $w$ (1 if $v$ and $w$ are connected; 0 otherwise)

$k_{v}=\sum_{w} A_{v w}$ is the degree of $v$, and $k_{w}=\sum_{v} A_{v w}$ is the degree of $w$

$m=\frac{1}{2} \sum_{v w} A_{v w}$ is the total number of possible non-oriented edges in the graph

$\delta\left(c_{v}, c_{w}\right)$ is the community function for $v$ and $w: 1$ if $v$ and $w$ are in the same community; 0 otherwise.

5 The spin glass methods (Reichardt, Bornholdt, 2006) use the Hamiltonian Potts model $\mathrm{H}[\{s\}]$ of a partition $s$, which measures the distance between the nodes according to their direct or indirect links to the networks $J_{v w}$ and based on their membership within the classes being partitioned $\delta\left(s_{v}, s_{w}\right)$ :

$$
\mathrm{H}[\{s\}]=-\sum_{v w} J_{v w} \delta\left(s_{v}, s_{w}\right)
$$

The spin glass model takes into account the existing links as well as the missing links inside and between classes. Then, $\mathrm{H}[\{s\}]$ is calculated for 4 cases:

$$
\mathrm{H}[\{s\}]=\underbrace{-\sum_{v \neq w} a_{v w} J_{v w} \delta\left(s_{v}, s_{w}\right)}_{\text {internal_links }}+\underbrace{\sum_{v \neq w} b_{v w}\left(1-J_{v w}\right) \delta\left(s_{v}, s_{w}\right)}_{\text {internal_non_links }}+\underbrace{\sum_{v \neq w} c_{v w} J_{v w}\left(1-\delta\left(s_{v}, s_{w}\right)\right)}_{\text {external_links }}+\underbrace{\sum_{v \neq w} d_{v w}\left(1-J_{v w}\right)\left(1-\delta\left(s_{v}, s_{w}\right)\right)}_{\text {external_non_links }}
$$

The model measures both intra-community and inter-community links. It also evaluates the "temperature", which is minimized when the network is far to randomly graph (Blatt et al., 1996). It calculates different partitions, maximizing their modularity and 
Rozenblat, C., Zaidi, F., \& Bellwald, A. (2017). The multipolar regionalization of cities in multinational firms' networks. Global Networks, 17(2), 171-194.

minimizing the temperature.

Acknowledgments:

The research has supported by the FP7 FET MULTIPLEX on Complex System Science regrouping essentially physicists. In this group, we would like to specifically acknowledge Panos Argyrakis, Michael Maragakis from Aristotle university in Thessaloniki, Shlomo Havlin from Bar Ilan University in Tel Aviv, and Antonios Garas from ETHZ in Zurich, for their fruitful advices and discussions about multiple complex networks. We would like to thanks also the Labri team in the Bordeaux University who develop the TULIP software we used for graph visualizations. 